\title{
Study on XLPE Cable Voltage Withstand Test and Its Circuit Model
}

\author{
Ding Yixuan ${ }^{1,}$,, Xu Deguang ${ }^{2, b}$, Li Jihui ${ }^{3, ~ c}$, Wang Wentao ${ }^{4,}$, , Wang \\ Hongqiang ${ }^{5, e}$ \\ ${ }^{1}$ School of Electrical Engineering, Zhengzhou University, Zhengzhou 450001, China \\ ${ }^{2}$ School of Electric Power, North China University of Water Resources and Electric Power, \\ Zhengzhou 450011, China \\ ${ }^{3}$ State Grid Henan Shenqiu County Electric Power Supply Company, Shenqiu 466300, China \\ ${ }^{4}$ State Grid Henan Huaiyang County Electric Power Supply Company, Huaiyang 466700, China \\ ${ }^{5}$ State Grid Xinxiang Electric Power Supply Company, Xinxiang 453000, China \\ a875658440@qq.com, b526040253@qq.com, ' 1420498726 \\ @qq.com, ${ }^{\mathrm{d}} 185898201 @ q q . c o m,{ }^{\mathrm{e}}$ wanghq4747@163.com
}

Keywords: XLPE; power cable; voltage withstand test; circuit model

\begin{abstract}
Analyze the application of resonant voltage withstand test in the XLPE cable voltage withstand test, and the two methods of variable frequency resonant voltage withstand test were compared by an example. By comparison, the resonant voltage test method can effectively simulate the field voltage withstand test of XLPE cable is found. Through the research of the traditional frequency conversion resonance voltage withstand test circuit, a new voltage withstand test model of cable is proposed, and models of young and old are compared by means of the spot testing, the conclusion of the new circuit model can be more accurate to complete the calculation of AC voltage withstand test is validated.
\end{abstract}

\section{Introduction}

Due to its excellent electrical performance and heat-resistant quality, cross-linked polyethylene cable is widely used in power distribution network, industrial plant and other areas which involve a large amount of electricity utilization. Under normal circumstances, power cable insulation may stay intact for a large amount of time, however, in actual operation, there are various factors for the malfunction of power cable insulation. Because of the features of cable materials and other objective factors such as the operating environment, cable insulation performance may occur different forms of aging due to the influence of different factors [1]. The aging forms of cross-linked polyethylene cable insulation are mainly electrical tree aging, water-tree aging, thermal aging, chemical corrosion aging, mechanical compound aging and etc. [2]. Studies have found that water-tree aging may cause severe damage to the insulation of cross-linked polyethylene cable. Therefore, in order to guarantee the safe and stable operation of the power systems, it is extremely essential to perform dielectric withstand voltage test when cable installation is completed and during maintenance, in order to comprehend their insulation features. This paper is a comparative analysis on current and commonly used variable frequency resonance testing methods, it is also a modification on the calculation model of traditional alternate current variable frequency voltage withstand test.

\section{Research on the method of alternate current resonant voltage withstand test}

\section{Variable frequency series resonant test method}

Variable frequency series resonant test method uses the resonant reactor in the series circuit and the capacitance of the test object to resonant, the excitation transformer only needs to provide very low voltage to reach the high voltage which the capacitance of the test object needs for the test. This reduces the volume and weight of the tester, it also lowers the requirements of the tester and 
the costs, it raises the economical efficiency and effectiveness of the test [3]. Schematic diagram of experimental set-up is shown as Figure 1.

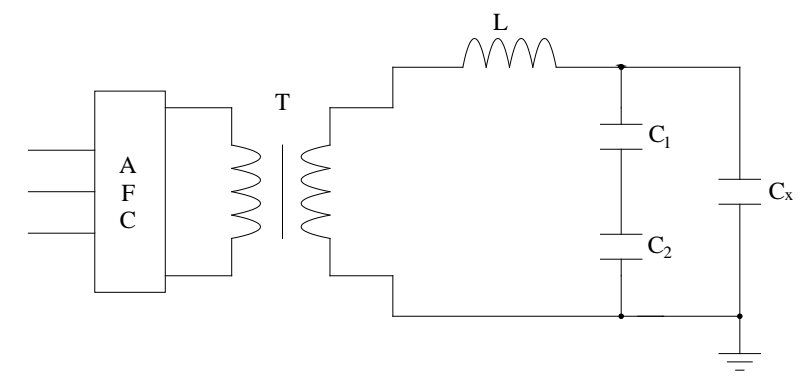

Fig.1 Schematic diagram of frequency variable serial resonance tester

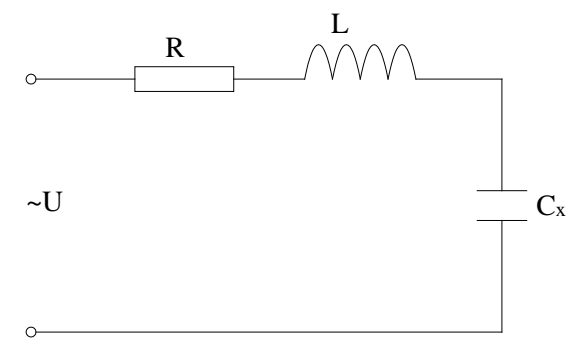

Fig.2 Equivalent circuit diagram of frequency variable serial resonance test

Figure 2 is the equivalent circuit diagram of frequency variable serial resonance test, among which $U$ is the side output voltage of excitation transformer high voltage; $L$ is high voltage reactor; $C_{\mathrm{X}}$ is the capacitance of test object; $R$ is the equivalent resistance in the circuit.

Adjust the power frequency to make the test circuit meet the resonant requirements,

Voltage of the test object capacitance

$$
U_{C}=U_{L}=I \cdot X_{L}=\frac{U}{R} X_{L}=Q U
$$

Among which, $Q=\frac{X_{L}}{R}$ is the quality factor of the testing circuit.

Reactive power consumption of test object capacitance

$Q_{C}=U_{C} I=Q U I$

Excitation transformer output power

$$
S=U I=\frac{Q_{C}}{Q}
$$

According to the analysis above, the needed power capacity of variable frequency series resonant test is only $1 / Q$ of the testing capacity, which lowers the requirements of the tester on a large extent.

\section{Frequency variable serial-parallel resonance test}

When the test object has long line length cable or other high capacity electrical equipment, the loop current in frequency variable series resonant test method is usually strong, sometimes it may even exceed the rated current of certain equipment in the circuit. Frequency variable serial-parallel resonance test makes a parallel connection between the reactor and the tested electrical equipment to compensate part of capacity current of the tested object, which reduces the loop current, lowers the requirements of electrical tester capacity. Such method has better practicability for large capacity testers. Schematic diagram of frequency variable serial-parallel resonance test is shown as Figure 3. 


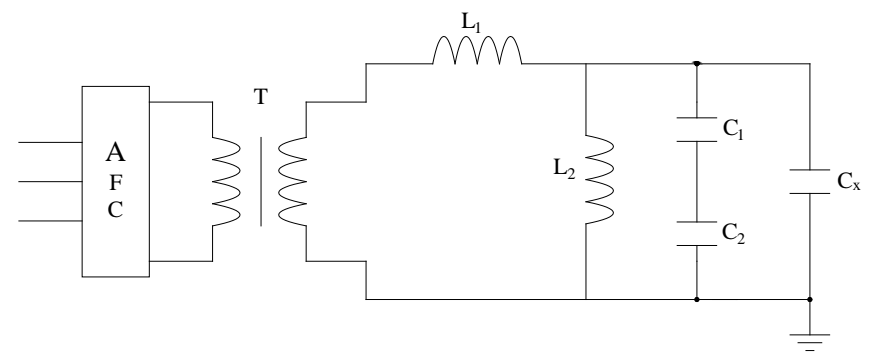

Fig.3 Schematic diagram of frequency variable serial-parallel resonance test

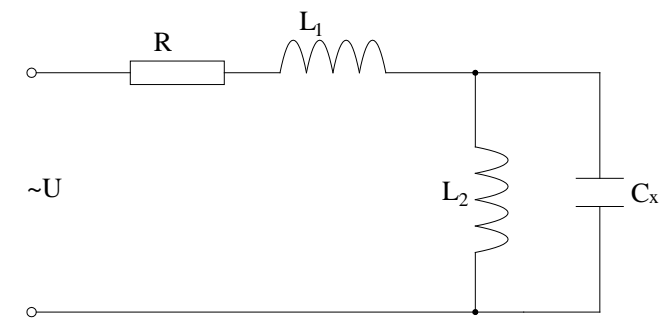

Fig.4 Equivalent circuit diagram of frequency variable serial-parallel resonance voltage withstand test

Figure 4 is the equivalent circuit diagram of frequency variable serial-parallel resonance voltage withstand test. Among which, $U$ is the side output voltage of high voltage excitation transformer; $L_{1}$ and $L_{2}$ is high voltage reactor; $C_{\mathrm{X}}$ is the capacitance of test object; $R$ is the equivalent resistance in the circuit.

Adjust the power frequency to make the test circuit meet the resonant requirements,

Voltage of the test object capacitance

$U_{C}=U_{L_{1}}=I \cdot X_{L_{1}}=\frac{U}{R} X_{L_{1}}=Q U$

Among which, $Q=\frac{X_{L_{1}}}{R}$ is the quality factor of the testing circuit.

$Q_{C}=U_{C} I_{C}=Q U I_{C}$

Excitation transformer output power

$S=U I<U I_{C}=\frac{Q_{C}}{Q}$

It is evident that the loop current in serial-parallel resonance test is less than the serial resonance test, which greatly reduces the requirements of power supply capacity, excitation transformer, frequency variable power supply. It also makes field cable withstand voltage test more convenient and flexible.

\section{Circuit model of cable dielectric withstand test analysis and testing}

\section{Establishment of new cable voltage circuit model}

Taking the existence of various kinds of distribution parameters into account, the equivalent circuit diagram of new AC voltage withstand test is shown as Figure 5. Among which, R1, L1 is internal excitation transformer impedance; R2 is the DC resistance of high voltage reactor; L2 is inductance of high voltage reactor; R3, R4, L3, C1 are all distributed parameter of the cable. Due to the fact that the resistance and reactance value of XLPE cables are so little that it can be ignored, figure 5 can be simplified into figure 6 . 


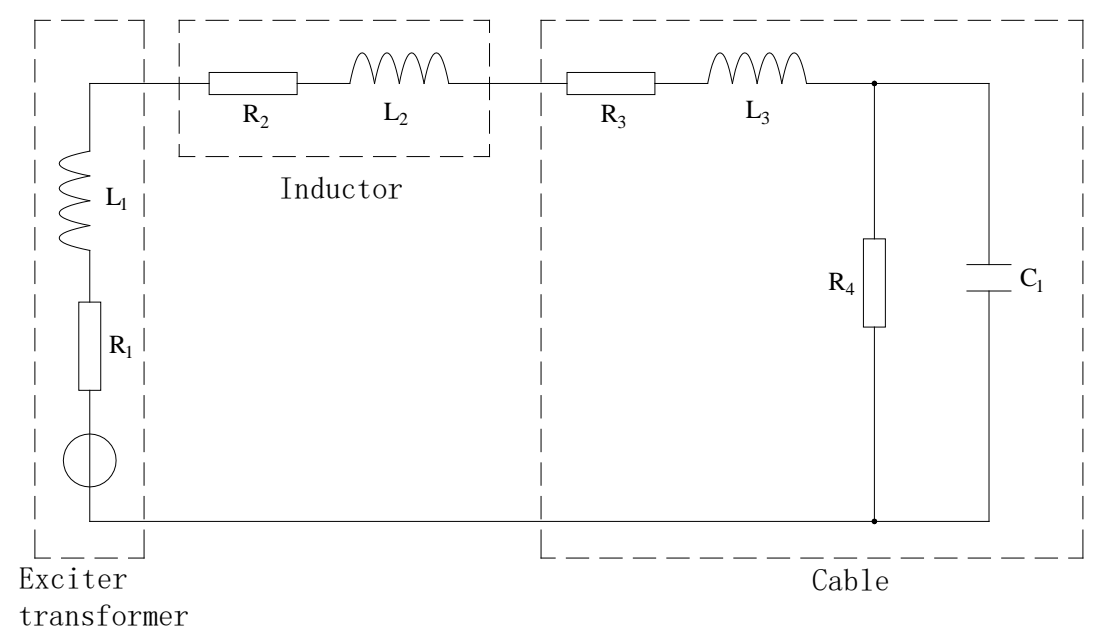

Fig.5 Equivalent circuit diagram of new Ac voltage withstand test

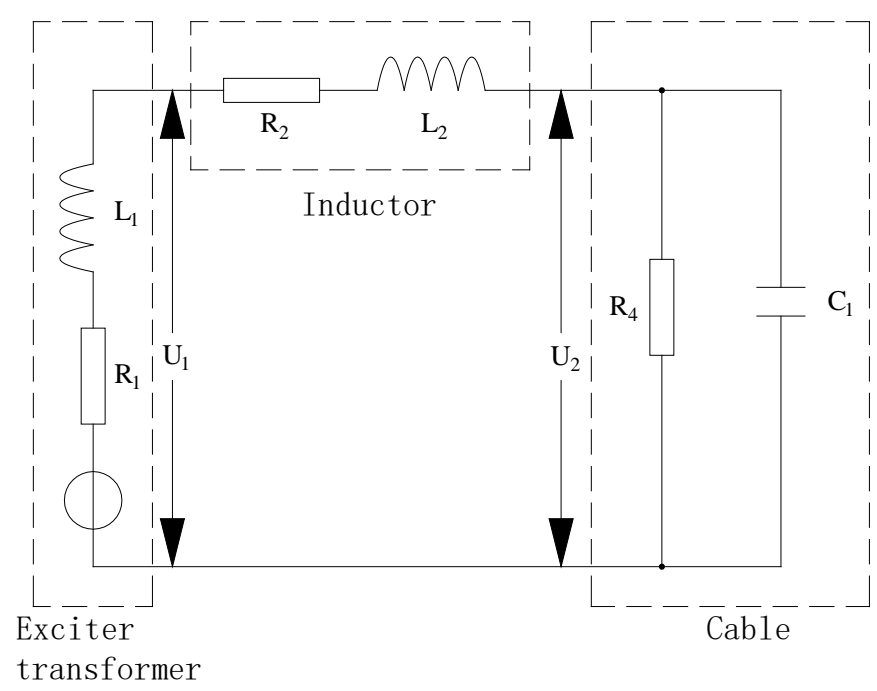

Fig.6 Equivalent circuit diagram of new Ac voltage withstand test

$U_{1}$ is side output voltage of high voltage excitation transformer; $U_{2}$ is the testing voltage of the tested cable.

The comparison between tested voltage and side output voltage of high voltage excitation transformer

$$
\frac{U_{2}}{U_{1}}=\frac{\left|R_{4} \frac{1}{j \omega C_{1}}\right|}{\left|\left(R_{2}+j \omega L_{2}\right)\left(R_{4}+\frac{1}{j \omega C_{1}}\right)+R_{4} \frac{1}{j \omega C_{1}}\right|}
$$

Compared to $L_{2}$, the value of $L_{1}$ can be ignored, therefore

$\omega=\frac{1}{\sqrt{\left(L_{1}+L_{2}\right) C_{1}}} \approx \frac{1}{\sqrt{L_{2} C_{1}}}$

\section{Also}

$$
\frac{1}{\omega C_{1}}=\omega L_{2}=R_{0}
$$

Bring it into (2), we can get

$$
\frac{U_{2}}{U_{1}}=\frac{R_{4} R_{0}}{\left|R_{4} R_{2}+R_{0}^{2}-j R_{2} R_{0}\right|}
$$

The quality factor in theory

$$
Q=\frac{1}{R} \sqrt{\frac{L}{C}}=\frac{R_{0}}{R_{2}}
$$


Make $\frac{R_{4}}{R_{2}}=m$

then,

$$
\frac{U_{2}}{U_{1}}=\frac{m}{\left|m+Q^{2}-j Q\right|} Q
$$

\section{The comparison of the new and old calculation methods}

The cable in field testing is cross-linked polyethylene cable which is to be put in operation soon in a city in northern Henan. The cable type is YJLW03-64/110kV-1×240, the voltage level is $110 \mathrm{kV}$, length $0.6072 \mathrm{kM}$, the capacity is $0.08865 \mu \mathrm{F}$.

Because the length of the test is short, frequency variable serial resonance test is used, the testing voltage is $126 \mathrm{kV}$ [4]. Equipment for the test are: frequency variable power supply type VFSR $-\mathrm{P}-1$, rated capacity $50 \mathrm{~kW}$, frequency output $20 \sim 400 \mathrm{~Hz}$, three-phase input voltage $380 \mathrm{~V}$, output voltage $0 \sim 350 \mathrm{~V}$, output current $0 \sim 571 \mathrm{~A}$; excitation transformer type $\mathrm{YD}^{-50 / 15}$, rated capacity 50kVA, frequency range $30 \sim 300 \mathrm{~Hz}$, high-tension winding voltage range $5 \sim 15 \mathrm{kV}$, current range $3.33 \sim 10 \mathrm{~A}$, low-tension winding rated voltage $350 \mathrm{~V}$, rated current 143A; excitation transformer type HVFR-650/130, frequency range $20 \sim 300 \mathrm{~Hz}$, rated inductance $125 \mathrm{H}$, coil resistance $180 \Omega$, pressure time $60 \mathrm{~min}$, rated current $5 \mathrm{~A}$, voltage $130 \mathrm{kV}$.

1) Calculation results of traditional cable withstand voltage circuit model

Equivalent circuit diagram of traditional serial resonance withstand voltage model is shown as Figure 2, use one excitation transformer, meanwhile, pressurize the cable. Of which, $R=180 \Omega$, $L=125 \mathrm{H}, C_{X}=0.08865 \times 10^{-6} \mathrm{~F}$.

Output current of frequency variable power supply

$$
I_{P O}=144 \mathrm{~A}
$$

The working efficiency of frequency variable power supply is around 75\%, therefore, input current of frequency variable power supply in theory

$$
I_{P I}=\frac{14.2 \times 144}{0.75 \times \sqrt{3} \times 380}=4.2 \mathrm{~A}
$$

2) Calculation results of new cable withstand voltage circuit model

Adopt the new cable withstand voltage circuit model, equivalent circuit diagram is shown as Figure 8. The parameter values are: $R_{1}=20 \Omega, R_{2}=180 \Omega, R_{4}=800 \mathrm{k} \Omega$, $L_{1}=5 \mathrm{H}, L_{2}=125 \mathrm{H}, C_{1}=0.08865 \times 10^{-6} \mathrm{~F}$. Parameters of excitation transformer are manufacturer calibration value, the equivalent resistance, inductance, conductance and other parameters are all given by the cable manufacturer.

According to the circuit model above, the calculated parameters are as follows:

Output current of frequency variable power supply

$$
I_{P O}=142 \mathrm{~A}
$$

The working efficiency of frequency variable power supply is around $75 \%$, therefore, output current of frequency variable power supply in theory is

$$
I_{P I}=\frac{150 \times 142}{0.75 \times \sqrt{3} \times 380}=43.2 \mathrm{~A}
$$

The comparison of the new and old model results and field measured value is shown as Table 1 .

It can be seen from the comparative results that compared to the calculation of traditional simple model, using the results of new cable withstand voltage testing circuit model are much closer to the actual measured value. 
Tab. 1 Comparison between the results of the new and old models and the measured results

\begin{tabular}{|c|c|c|c|c|c|c|c|}
\hline \multirow{2}{*}{ Equipment } & $\begin{array}{c}\text { Variable } \\
\text { frequency } \\
\text { power supply }\end{array}$ & $\begin{array}{c}\text { Input } \\
\text { voltage/V }\end{array}$ & $\begin{array}{c}\text { Input } \\
\text { current/A }\end{array}$ & $\begin{array}{c}\text { Input } \\
\text { frequency/ } \\
\mathrm{Hz}\end{array}$ & $\begin{array}{c}\text { Output } \\
\text { voltage/ } \\
\mathrm{V}\end{array}$ & $\begin{array}{c}\text { Output } \\
\text { current/ } \\
\mathrm{A}\end{array}$ & $\begin{array}{c}\text { Output } \\
\text { frequency/ } \\
\mathrm{Hz}\end{array}$ \\
\hline \multirow{2}{*}{$\begin{array}{c}\text { Variable } \\
\text { frequency } \\
\text { power supply }\end{array}$} & $\begin{array}{c}\text { Traditional } \\
\text { model }\end{array}$ & 380 & 4.2 & 50.0 & 14.2 & 144 & 47.8 \\
\cline { 2 - 8 } & New model & 380 & 43.2 & 50.0 & 150.0 & 142 & 46.9 \\
\cline { 2 - 8 } & Field test & 380 & 58.0 & 50.0 & 200.0 & 146 & 55.0 \\
\hline \multirow{2}{*}{$\begin{array}{c}\text { Excitation } \\
\text { transformer }\end{array}$} & $\begin{array}{c}\text { Traditional } \\
\text { model }\end{array}$ & 14.2 & 144 & 47.8 & 610 & 3.35 & 47.8 \\
\cline { 2 - 8 } & \begin{tabular}{c} 
New model \\
\cline { 2 - 8 } Cable
\end{tabular} & 150.0 & 142 & 46.9 & 6430 & 3.30 & 46.9 \\
\hline \multirow{2}{*}{ Field test } & 200.0 & 146 & 55.0 & 8500 & 3.41 & 55.0 \\
\cline { 2 - 8 } & Traditional & 126000 & 3.35 & 47.8 & & & \\
\cline { 2 - 8 } & New model & 126000 & 3.30 & 46.9 & & & \\
\hline
\end{tabular}

\section{Summary}

This paper puts forward a new calculation model of testing circuit based on traditional frequency variable serial resonance test, which takes more factors into account. Theoretical analysis and field investigation results show that the calculation results of this model may provide much more accurate comparable data for the selection of field testing equipment. Both methods of alternate current resonant voltage withstand test can efficiently inspect the insulation feature of cross-linked polyethylene cable. However, when in actual use, it should be selected according to site conditions.

\section{References}

[1] Wang, S. H., Ming-Xiang, W. U., Wen-Tang, H. U., Liu, Y., Wang, T., \& Zhou, H. Analysis on power cable operation in Zhejiang Grid. Zhejiang Electric Power(2012).

[2] Li Lang. High voltage power cable malfunction analysis and research. Southwest Jiaotong University(2013).

[3] Gu, Qing., Wang, Liang. Cable voltage test method and analysis of typical problems. Electric Engineering(2013).

[4] China National Standardization Management Committee. Power cables with cross-linked polyethylene insulation and their accessories for rated voltage of $110 \mathrm{kV}(\mathrm{Um}=126 \mathrm{kV})$ - Part 1:Test methods and requirements. China Standards Press(2014).

[5] Chen, Bin., Huo, Guang. Discussion on withstand voltage test of XLPE cable. Electrical Application(2010). 